1

"This is the peer reviewed version of the following article: Romero, C., Medina,

1

2

3

\section{Quantification of bioactive substances in Picual and Arbequina olive}

7 Concepción Romero ${ }^{\mathrm{a}}$, Eduardo Medina ${ }^{\mathrm{a}}, \mathrm{M}^{\mathrm{a}}$ Antonia Mateo ${ }^{\mathrm{b}}$ and Manuel Brenes ${ }^{\mathrm{a},{ }^{*}}$

$8 \quad{ }^{a}$ Food Biotechnology Department, Instituto de la Grasa (IG-CSIC), Campus University

9 Pablo de Olavide, Ctra. Utrera km 1, 41013-Seville, Spain

$10{ }^{b} J a e n c o o p$ SCA, Avda. de Valencia s/n, 23330-Villanueva del Arzobispo, Jaén, Spain

\section{leaves and fruit}

11

(1)

*Correspondence to: Manuel Brenes, Food Biotechnology Department, Instituto de la Grasa (IG-CSIC), Campus University Pablo de Olavide, Ctra. Utrera km 1, 41013Seville, Spain. E-mail brenes@cica.es

Running title: Bioactive substances in olive leaves and fruit 
1 Abstract

2

3 BACKGROUND: Olive leaves and fruit possess bioactive substances such as phenolic 4 compounds and triterpenic acids that can be obtained from olive by-products generated 5 during olive oil extraction. The aim of this work was the characterization and 6 quantification of them in Picual and Arbequina cultivars from different locations and for 7 several seasons in both olive leaves and fruit.

8 RESULTS: The major phenolic compound identified in the leaves was oleuropein, and 9 the total content of phenolic compounds in this material reached $70 \mathrm{~g} \mathrm{~kg}^{-1}$ fresh weight. 10 The leaves were also rich in triterpenic acids $\left(20 \mathrm{~g} \mathrm{~kg}^{-1}\right.$ fresh weight), with oleanolic 11 being the most concentrated in them. With regard to olives, oleuropein and 12 demethyloleuropein were the main phenolic compounds in the pulp of Picual and 13 Arbequina cultivars, and the total concentration of these phenolic compounds reached $143.5 \%$ fresh weight. Olives can also be an important source of triterpenic acids although 15 mainly the skin part, where maslinic and oleanolic acids are concentrated.

16 CONCLUSIONS: Olive leaves can contain up to $70 \mathrm{~g} \mathrm{~kg}^{-1}$ phenolic compounds and 20 $17 \mathrm{~g} \mathrm{~kg}^{-1}$ triterpenic acids, and olive fruit up to $35 \mathrm{~g} \mathrm{~kg}^{-1}$ of the former and $3 \mathrm{~g} \mathrm{~kg}^{-1}$ of the 18 latter. It must also be noted that this level was constant between seasons and orchard 19 location.

21 Keywords: olive; phenolic; triterpene; oleuropein; maslinic; oleanolic 


\section{INTRODUCTION}

3 The worldwide production of olive oil accounts for ca. 3 million tons per year, and 4 around half of them are produced in Spain, Picual as the most important cultivar grown 5 in this country. Moreover, the number of olive trees of the Arbequina cultivar is highly 6 increasing both in Spain and worldwide because of the appreciated organoleptic 7 characteristics of its oil and the good adaptation of the tree to super-high-density 8 hedgerow cultivation.

9 Both olive cultivars are mainly intended for olive oil production that gives rise to 10 olive pomace (alperujo) and leaves as the main by-products, which are rich in bioactive 11 substances such as phenolic compounds and triterpenic acids. They have been found to 12 exert important effects such as antioxidant, anti-inflammatory, antimicrobial and 13 antitumor agents, among others. ${ }^{1-4}$ In addition, the resistance of these olive trees to 14 insect and microbe attack has also been associated to the presence of phenolic and 15 triterpene compounds. ${ }^{5-7}$ Consequently, there have been many studies and patents with 16 the aim of obtaining extracts rich in these substances from olive by-products.

Although the chemical characterization of phenolic and triterpene substances in olive products is well-documented, ${ }^{8-11}$ many of these studies were carried out with olives and leaves picked from experimental orchards; few samples were used or they were analyzed during one unique crop season. ${ }^{12-15}$ In addition, contradictory data on the concentration of these substances in olive material can be found in the literature, and they are scarce on the phenolic and triterpenic composition of the different parts of the olives (skin, seed and pulp). ${ }^{16-18}$ Hence, a deep knowledge of the amount of them in olive leaves and fruit cultivated under common agronomic conditions for several seasons is required, mainly if these bioactive substances are to be extracted from olive by-products.

The main objective of this work was to quantify the phenolic and triterpenic substances in olive leaves and fruit of the Picual and Arbequina cultivars grown in different areas of the province of Jaen, which is the main Spanish producer of olive oil.

30 The effect of the degree of olive maturation on the content in these bioactive substances 31 was also assessed. 
1

2 MATERIALS AND METHODS

3 Samples

4 Samples from olive leaves and fruit (Olea europaea L.) of the Picual and Arbequina

5 varieties were used in this study. Leaves from 7 orchards located in the north of the 6 province of Jaen (south of Spain) were obtained from trees of the Picual variety in 7 November, January and April during the 2012/2013 season. Leaves of trees of the 8 Arbequina variety were also picked on the same dates from only one orchard. All 9 samples were collected in triplicate from all sides and orientations of 9 olive trees. 10 During the 2013/2014 season, the olive leaves were obtained from 3 orchards of the 11 Picual variety and one of Arbequina on the same dates as the former season.

Olive fruits of the Picual variety were picked from the same 7 and 3 orchards used for leaf characterization during the 2012/2013 and 2013/2014 seasons, respectively. The same orchard of Arbequina variety was used for olive samples of the two seasons. The fruits were harvested in December with three different degrees of maturation: (i) green-yellowish skin (green), (ii) reddish-brown skin (purple), and (iii) black skin with white flesh (black). As was done with leaves, each sample of olive fruit was collected in triplicate from all sides and orientation of 9 olive trees.

Olives of the Picual variety were also picked from 4 orchards in December (2012/2013 season) at the two extreme degrees of maturation (green and black), and phenolic and triterpenic compounds were analyzed in the pulp, skin and seed.

It must be noted that all samples (olive and leaf) were immediately transferred to the laboratory and analyzed on the same day without any storage period.

The olive orchards were cultivated under standard cultural practices and trees were irrigated ad libitum to avoid water stress.

\section{Analysis of phenolic and oleosidic compounds}

The extraction of phenolic and oleosidic compounds from the olive pulp was based on the methodology proposed elsewhere. ${ }^{18}$ Around $10 \mathrm{~g}$ of fresh olive pulp was mixed in 
1 an Ultra-turrax homogenizer with $30 \mathrm{~mL}$ of dimethyl sulfoxide (DMSO). After $30 \mathrm{~min}$ 2 of resting contact, the mixture was centrifuged at $6000 \mathrm{~g}$ for $5 \min \left(22^{\circ} \mathrm{C}\right)$, and $0.25 \mathrm{~mL}$ 3 of the supernatant were diluted with $0.5 \mathrm{~mL}$ of DMSO plus $0.25 \mathrm{~mL}$ of $0.2 \mathrm{mM}$ of 4 syringic acid in DMSO (internal standard). The extraction of these substances from the 5 skin and the seed was made similarly to the olive pulp as described above, but this time 6 the mixing ratio was $0.1 \mathrm{~g}$ of olive skin or seed and $0.5 \mathrm{~mL}$ of DMSO.

$7 \quad$ Samples were filtered through a $0.22 \mu \mathrm{m}$ pore size nylon filter, and an aliquot $8(20 \mu \mathrm{L})$ was injected into the chromatograph. The chromatographic system consisted of 9 a Waters 717 plus autosampler, a Waters 600 pump, a Waters column heater module, and a Waters 996 photodiode array detector operated with Empower.2 software 11 (Waters, Inc.). A $25 \mathrm{~cm} \mathrm{x} 4.6 \mathrm{~mm}$ i. d., $5 \mu \mathrm{m}$, Spherisob ODS-2 (Waters, Inc.) column 12 at a flow rate of $1 \mathrm{~mL} \mathrm{~min}^{-1}$ and a temperature of $35^{\circ} \mathrm{C}$, was used in all experiments. 13 Separation was achieved by gradient elution using (A) water ( $\mathrm{pH} 2.5$ adjusted with $14 \quad 0.15 \%$ phosphoric acid) and (B) methanol. The initial composition was $90 \% \mathrm{~A}$ and $10 \%$ 15 B. The concentration of B was increased to $30 \%$ over 10 min and was maintained for 20 16 min. Subsequently, B was raised to $40 \%$ over $10 \mathrm{~min}$, maintained for $5 \mathrm{~min}$, and then 17 increased to $50 \%$. Finally, B was increased to 60 , 70, and $100 \%$ in 5 min periods. The 18 initial conditions were reached in $10 \mathrm{~min}$. Chromatograms were recorded at $280 \mathrm{~nm}$ and $240 \mathrm{~nm}$ for phenolic and oleosidic compounds, respectively.

The evaluation of each compound was performed using a regression curve with the corresponding standard. Hydroxytyrosol, oleuropein, verbascoside, luteolin 7glucoside, rutin, and apigenin were purchased from Extrasynthese S. A. (Genay, France) and tyrosol, caffeic acid and $p$-coumaric acid from Sigma Chemical Co. (St Louis, MO, USA). Hydroxytyrosol-1-glucoside, caffeoyl ester of secologanoside, and comselogoside were quantified using the response factors of hydroxytyrosol, caffeic acid, and $p$-coumaric acid, respectively. Salidroside and ligustroside were quantified using the response factor of tyrosol. Hydroxytyrosol-4-glucoside was obtained using an HPLC preparative system. All oleosidic compounds were quantified using the response 29 of oleoside 11-methyl ester. 
1 The water content of fruits and leaves was determined by weighing $3 \mathrm{~g}$ of the organ and

2 then oven drying at $105^{\circ} \mathrm{C}$ to constant weight.

3

\section{$4 \quad$ Analysis of sugars}

5 Fresh olive pulp $(25 \mathrm{~g})$ or olive leaf $(10 \mathrm{~g})$ was mixed with $5 \mathrm{~mL}$ of $7.5 \%$ sorbitol 6 (internal standard) and $50 \mathrm{~mL}$ of distilled water at $100{ }^{\circ} \mathrm{C}$. The mixture was 7 homogenized in Ultra-turrax equipment, and centrifuged at $6000 \mathrm{~g}$ for $5 \mathrm{~min}$. After that, 8 the supernatant was filtered through filter paper and the paste was washed twice with 30 $9 \mathrm{~mL}$ of distilled water at $100{ }^{\circ} \mathrm{C}$. The supernatant was collected in a $125 \mathrm{~mL}$ volumetric flask and distilled water was added to the mark. The solution was left at $5{ }^{\circ} \mathrm{C}$ for $24 \mathrm{~h}$ and $5 \mathrm{~mL}$ were filtered through a $0.22 \mu \mathrm{m}$ pore size nylon filter. Subsequently, $2 \mathrm{~mL}$ of the extract were de-salted by adding $1 \mathrm{~g}$ of cationic resin (Amberlite IR-120, FlukaChemieAG, Switzerland) and $1 \mathrm{~g}$ of anionic resin (Amberlite IR-96, Fluka). Samples were shaken occasionally during a $30 \mathrm{~min}$ de-salting period. An aliquot $(\approx$ $1 \mathrm{~mL}$ ) of the solution was centrifuged at $6000 \mathrm{~g}$ for $5 \mathrm{~min}$, and $20 \mu \mathrm{L}$ were injected into the chromatograph. The HPLC system was the same used for the phenolic analysis, and the detection was carried out with a Waters 410 differential refractometer detector. A Rezex RCM-monosaccharide $\mathrm{Ca}+(8 \%)$ column (300 mm x $7.8 \mathrm{~mm}$ i.d., Phenomenex) held at $85{ }^{\circ} \mathrm{C}$ with deionized water as the eluent at $0.6 \mathrm{~mL} / \mathrm{min}$ was used for sugar analyses. Sucrose, fructose, glucose, mannitol and sorbitol were purchased from Sigma Co. (St. Louis, USA).

\section{Analysis of triterpenic acids}

Ten grams of de-stoned and cut olive fruits or cut leaves were desiccated at $105^{\circ} \mathrm{C}$ until weight stabilization. Subsequently, $1 \mathrm{~g}$ of dry and triturated olive pulp or leaf were mixed in a $10 \mathrm{~mL}$ centrifuge tube with $4 \mathrm{~mL}$ of methanol/ethanol $(1: 1, \mathrm{v} / \mathrm{v})$ and vortexed for $1 \mathrm{~min}$, centrifuged at $6000 \mathrm{~g}$ for $5 \mathrm{~min}$ at $20^{\circ} \mathrm{C}$, and the solvent was separated from the solid phase. This step was repeated six times, and the pooled solvent extract was vacuum evaporated. The residue was dissolved in $4 \mathrm{~mL}$ of methanol, which was filtered through a $0.22 \mu \mathrm{m}$ pore size nylon filter and an aliquot $(20 \mu \mathrm{L})$ was injected into the liquid chromatograph. The chromatographic system and column were the same 
1 as those used for the phenolic compound analysis. The mobile phase 2 (methanol/acidified water with phosphoric acid at $\mathrm{pH} 3.0,92: 8, \mathrm{v} / \mathrm{v}$ ) was delivered to 3 the column at a flow rate of $0.8 \mathrm{~mL} \mathrm{~min}^{-1}$ and the eluate was monitored at $210 \mathrm{~nm}$.

4 Oleanolic and maslinic acids were quantified using external standards (Sigma, USA).

5

\section{Statistical analysis}

7 Statistical comparisons of the mean values for each experiment were performed by one8 way analysis of variance (ANOVA), followed by the Duncan's multiple range test ( $p<$ 9 0.05) using Statistica software version 8.0 (Stat-Soft, 2001).

\section{RESULTS AND DISCUSSION}

The sampling of olive leaves were taken in November and January because this is the harvesting period of olives and when leaves can be obtained at the olive oil mills as a by-product. They were also analyzed in April when olive trees are pruned. The data in Table 1 on the concentration of phenolic compounds in leaves of the Picual and Arbequina cultivars show great differences with respect to the reported values. Many previous studies have been carried out during the time course of fruit ripening from May to December but no clear conclusions have been obtained on the phenolic compounds in the leaves. ${ }^{15,19-20}$ However, our data indicate that the concentration of oleuropein was much higher in November than in the following months, whereas the rest of the phenolic compounds increased their concentrations from November onwards, which was observed for both Picual and Arbequina cultivars. These differences cannot be attributed to changes in the water content of the leaves harvested from November to April (Table S1), although a much higher percentage of water was always found in leaves of the Arbequina $\left(\sim 520 \mathrm{~g} \mathrm{~kg}^{-1}\right)$ than Picual $\left(\sim 430 \mathrm{~g} \mathrm{~kg}^{-1}\right)$ cultivar.

First, these substances were found in a much higher concentration than recorded in the literature. Moreover, the four main phenolic compounds detected were oleuropein, verbascoside and the hydroxytyrosol glucosides. By contrast, the presence of metabolites from the hydrolysis of the secoiridoid glucosides such as hydroxtyrosol and tyrosol was not observed. The concentration of oleuropein in the seven samples of 
1 Picual leaves collected from seven different growing areas of the province of Jaen 2 ranged from $47 \mathrm{~g} \mathrm{~kg}^{-1}$ for those picked in April up to $72 \mathrm{~g} \mathrm{~kg}^{-1}$ for those in November.

3 Up to now, the concentration of oleuropein and total phenolic compounds in the leaves 4 of Spanish and Italian cultivars did not exceed 1-3\% fresh weight. ${ }^{8,15,19-20,21}$ In this 5 study, samples were directly analyzed without any drying or storage period which may 6 explain the high amount of phenolic compounds measured. It must be noted that during 7 the drying and storage of leaves enzymatic reactions occur that can reduce the level of 8 these substances as well as originate metabolites from their hydrolysis. The content of 9 the hydroxytyrosol glucosides was also higher than reported in the literature; ${ }^{4}$ their 10 concentration increased from November to April, while that of oleuropein decreasing in 11 both Picual and Arbequina olive leaves (Table 1). The concentration of verbascoside 12 and other minor compounds also increased from November to April.

Concerning oleosides, a similar behavior to oleuropein was found for all of them 14 (Table S2), and the maximum concentration was reached in November. Besides, the 15 concentration of oleoside and oleoside 11-methyl ester was always higher in Picual than 16 Arbequina leaves, and the opposite was observed for secoxyloganin and 17 secologanoside.

As was found in Picual leaves, the main phenolic compound in the fruit was oleuropein, its concentration slightly decreasing with maturation degree (Table 2). By contrast, this secoiridoid glucoside was detected only in the pulp of green Arbequina olives, whereas demethyloleuropein was the main phenolic compound in this cultivar, whose concentration slightly decreased as ripening increased. The presence of demethyloleuropein in Arbequina olives has previous been reported, ${ }^{13}$ but not at a high concentration of $1 \%$ fresh weight. ${ }^{9}$ Similarly, the concentration of oleuropein in Picual olives was found to be around $18 \mathrm{~g} \mathrm{~kg}^{-1}$ fresh weight, which is much higher than previous data. ${ }^{9}$ The high content of hydroxtyrosol glucosides in the pulp of both cultivars must also be noted, as has been documented in olives intended for table olives. $^{18}$

Many studies have shown a decrease in total polyphenols, particularly oleuropein, with the time course of olive ripening, ${ }^{22-23}$ which has also been observed in 31 this work. By contrast, many other phenolic compounds such as hydroxtyrosol 32 glucosides, verbascoside and rutin increased with olive maturation (Table 2). In 
1 particular, a decrease in hydroxytyrosol glucosides during olive maturation has been 2 previously reported, ${ }^{13}$ but the opposite has also been found. ${ }^{24}$ Indeed, it has been 3 observed in this work that while the concentration of oleuropein decreases with time in 4 both the fruit and leaves of Picual and Arbequina cultivars, many others phenolic 5 compounds increase (Tables 1 and 2). The moisture of the fruit did not significantly 6 change with olive maturation (Table S3), although, as happened with the leaves, this 7 parameter was higher for the Arbequina than Picual cultivar, with these differences 8 registering higher during the 2012/2013 than the 2013/2014 season.

9 There is scarce information on the presence of oleosidic substances in olives. ${ }^{25}$ Talhaoui et al (2015c) did not observe any changes or only a slightly decrease in these compounds in olives harvested from October to December, which is in agreement with the data reported in Table S4. In this study, the concentrations of oleoside 11-methyl ester and secoxyloganin were higher in olives of the Arbequina than Picual cultivar, and the opposite trend was detected for oleoside and secologanoside.

The phenolic compounds were analyzed in different parts of olives of the Picual cultivar harvested with green/yellow and black color on the surface (Table 3). The most significant finding was the much higher concentration of these substances in the skin than in the pulp regardless of the degree of maturation. Surprisingly, there is little data revealing the enrichment of the skin of olives in these substances, ${ }^{18,26}$ which was found not only for oleuropein but for most of the phenolic compounds analyzed. As previously reported, the main phenolic compound in the seed was nuzhenide with a rather similar level for the both degrees of olive maturation studied. ${ }^{27}$ With regard to oleosides, none of them were detected in the seeds (Table S5), and secoxyloganin was not found in the skin of the fruit. Moreover, oleoside and secologanoside were more concentrated in the skin than in the pulp, whereas the opposite for oleoside 11-methyl ester was detected. The later substance is a precursor of oleuropein biosynthesis, and the lower content detected in the skin could be related to the higher concentration of oleuropein in this part of the olive. A trend to lower oleoside concentration in black than green olives was also observed, regardless of the part of the fruit.

The profile and concentration of phenolic compounds in olive leaves have been 31 proposed to discriminate among cultivars and cultivation zones. ${ }^{8,19,28}$ The data depicted 32 in Figure 1 indicate that the content of phenolic compounds in Picual leaves was not 
1 useful to discriminate among three cultivation zones in the province of Jaen, regardless

2 of the sampling time and season year. Seasonal changes have been reported in the 3 phenolic content of olive leaves, ${ }^{29-30}$ but this effect was not detected in this study 4 (Figure 1). Among the three cultivation zones analyzed, the phenolic content in olives 5 from Santisteban del Puerto (ST) presented the highest concentration for the two 6 seasons studied. A higher concentration of these substances was found in the olives of 7 the 2012/2013 season than the 2013/2014 season when they were harvested from 8 orchards located in Chilluevar $(\mathrm{CH})$ and Santisteban del Puerto (ST) but not 9 Villacarrillo (VI) regardless of the degree of maturation.

Triterpenic acids are other important bioactive substances analyzed in olives and leaves. The skin of the fruit is very rich in triterpenic acids, ${ }^{16}$ which was confirmed in 12 this study for olives collected with two degrees of ripeness (Table 3). The concentration 13 of maslinic acid was higher than oleanolic in both skin and pulp although the 14 differences were higher in the pulp. There are few and contradictory data on the content 15 of triterpenic acids in olive pulp. Guinda et al (2010) reported lower concentrations than $161 \mathrm{~g} \mathrm{~kg}^{-1}$ in the olives of the Picual and Arbequina cultivars, whereas Fernández17 Hernández et al (2015) found a concentration higher than $25.5 \mathrm{~g} \mathrm{~kg}^{-1}$ in olive oil mill 18 paste (alperujo). Figure 2 shows a rather similar concentration of triterpenic acids in both cultivars ranging from 2400 to $3100 \mathrm{mg} \mathrm{kg}^{-1}$ fresh weight that coincides with our previous data. ${ }^{11}$ Peragón (2013) followed the evolution of these substances in the olives of the Picual and Cornezuelo cultivars during maturation and observed a drastic decrease in their concentration at the first step of ripening but from October to December the evolution was contradictory. In this study, the concentration of triterpenic acids decreased from green to black olives of the Picual cultivar (Figure 2), and it also occurred from green to purple olives of the Arbequina cultivar but not significantly. These findings cannot be attributed to changes in the water content of the fruit (Table S3). Besides, the concentration of maslinic was always much higher than that of oleanolic acid.

In contrast, the concentration of oleanolic acid was much higher than that of maslinic acid in the leaves (Figure 3), as previously reported. ${ }^{10}$ The total concentration 31 of triterpenic acids ranged between 11 and $21 \mathrm{~g} \mathrm{~kg}^{-1}$ fresh weight, values similar to 32 those found by other researchers. ${ }^{15,32}$ Similarly, the content of these substances was always higher in leaves of the Picual than Arbequina cultivar, and a slight decrease was 
1 detected from sampling in November to April (Figure 3). In fact, the concentration of

2 these substances in the Picual leaves obtained from three different orchards during two

3 consecutive seasons was very similar (Figure 4) regardless of the location of the trees,

4 although a slightly lower value was observed in the olives picked in April. It must be

5 noted that the orchards were situated at different altitudes in the province of Jaen.

6 Moreover, differences in the concentration of triterpenic acids in the olives between

7 seasons were minimal, and the content in fruit harvested with black color tended to be

8 lower than with the green color (Figure 4).

9 Sugars are the carbon source for microorganisms during table olive 10 fermentation; ${ }^{33}$ the precursors in the biosynthesis of lipids thereby a good correlation 11 between the content in olives of lipids and sugars has been found, ${ }^{23}$ but they can also be 12 a good source of bioactive substances such as mannitol. ${ }^{15}$ Figure 5 shows the 13 concentration of sugars in the olives and leaves of the Picual and Arbequina cultivars. 14 As expected, glucose, sucrose, fructose and mannitol were the main sugars identified in 15 these materials. Glucose was the main sugar in both the fruit and leaves although the 16 concentration of mannitol was similar to glucose in the leaves of the two cultivars 17 studied, which is in disagreement with results obtained by other, ${ }^{34}$ who found a rather 18 similar concentration of mannitol and glucose in the pulp of the olives. The concentration of mannitol in the leaves was similar in both cultivars analyzed and both sampling times, which reached $20 \mathrm{~g} \mathrm{~kg}^{-1}$ fresh weight. This substance is useful for pharmaceutical purposes and has been attributed to beneficial properties for health. In fact, it can be selectively extracted from olive leaves by using ethanol as solvent. ${ }^{15}$

\section{CONCLUSIONS}

Picual is the olive cultivar most employed worldwide for the extraction of the healthy fat, olive oil. However, it can also be a good source of bioactive substances obtained from the by-products generated during oil extraction, particularly phenolic compounds and triterpenic acids. The leaves of this cultivar but also those of the Arbequina cultivar possess a very high concentration in both phenolic and triterpene substances when obtained from orchards cultivated under common agronomic conditions. The contents in phenolic compounds and triterpenic acids in leaves can reach up to $70 \mathrm{~g} \mathrm{~kg}^{-1}$ and $20 \mathrm{~g}$ 
1 seasons and orchard location, which is very important for a continuous supply of raw

2 material to a future factory of bioactive substances. Olives can also have an important

3 concentration in triterpenic acids, mainly in the skin, although they are particularly rich

4 in phenolic compounds that can reach $35 \mathrm{~g} \mathrm{~kg}^{-1}$ fresh weight, with oleuropein and

5 demethyloleuropein being the main phenolics in the pulp of Picual and Arbequina

6 cultivars, respectively. These results will contribute to the knowledge of the presence of

7 phenolic and triterpene compounds in olive material suitable for the extraction of

8 bioactive substances in the future.

10 ACKNOWLEDGEMENTS

11 We are grateful to the Cooperatives of the Jaencoop SCA group for the supply of olive 12 material. This work was supported by the Spanish Government and European Feder 13 funds (project ASOAN, Interconecta ITC-20111073). We thank Alejandra Expósito and 14 Juan Antonio Espejo for technical assistance. 


\section{REFERENCES}

1 Lozano-Mena G, Sánchez-González M, Juan M E and Planas J, Maslinic acid, a natural phytoalexin-type triterpene from olives. A promising nutraceutical? Molecules 19:11538-11559 (2014).

2 Botsoglou E N, Govaris A K, Ambrosiadis I A and Fletouris D J, Olive leaves (Olea europaea L.) versus $\alpha$-tocopheryl acetate as dietary supplements for enhancing the oxidative stability of eggs enriched with very-long-chain $n-3$ fatty acids. J Sci Food Agric 93:20153-2060 (2013).

3 Medina E, Brenes M, García A, Romero C and De Castro A, Bactericidal activity of glutaraldehyde-like compounds from olive products. J Food Prot 72:2611-2614 (2009).

4 Talhaoui N, Taamalli A, Gómez-Caravaca A M, Fernández-Gutiérrez A and Segura-Carretero A, Phenolic compounds in olive leaves: Analytical determination, biotic and abiotic influence, and health benefits. Food Res Int 77:92-108 (2015a).

5 Kubo I, Matsumoto A and Takase I, A multichemical defense mechanism of bitter olive Olea europaea (Oleaceae). Is oleuropein a phytoalexin precursor? J Chem Ecol 11:251-263 (1985).

6 Zine El Aabidine A Z, Baissac Y, Moukhli A, Jay-Allemand C, Khadari B and El Modafar C, Resistance of olive tree to Spilocaea oleagina is meditated by the synthesis of phenolic compounds. Int J Agric Biol 12:61-67 (2010).

7 González-Coloma A, López-Balboa C, Santana O, Reina M and Fraga B M, Triterpene-based plant defenses. Phytochem Rev 10:245-260 (2011).

8 Japón-Luján R, Ruiz-Jiménez $\mathrm{J}$ and Luque de Castro M D, Discrimination and classification of olive tree varieties and cultivation zones by biophenol contents. J Agric Food Chem 54:9706-9712 (2006).

9 Gómez-Rico A, Fregapane G and Salvador M D, Effect of cultivar and ripening on minor components in Spanish olive fruits and their corresponding virgin olive oils. Food Res Int 41:433-440 (2008).

10 Guinda A, Rada M, Delgado T, Gutiérrez-Adánez $\mathrm{P}$ and Castellano $\mathrm{J} \mathrm{M}$, Pentacyclic triterpenoids from olive fruit and leaf. J Agric Food Chem 58:96859691 (2010). 
11 Romero C, García A, Medina E, Ruíz-Méndez M V, De Castro A and Brenes M, Triterpenic acids in table olives. Food Chem 118:670-674 (2010).

12 Talhaoui N, Gómez-Caravaca A M, Roldán C, León L, De la Rosa R, Fernández-Gutiérrez A and Segura-Carretero A, Chemometric analysis for the evaluation of phenolic patterns in olive leaves from six cultivars at different growth stages. J Agric Food Chem 63:1722-1729 (2015b).

13 Romero C, García P, Brenes M, García A and Garrido A, Phenolic compounds in natural Spanish olive varieties. Eur Food Res Technol 215:489-496 (2002).

14 Bouaziz M, Jemai H, Khabou W and Sayadi S, Oil content, phenolic profiling and antioxidant potential of Tunisian olive drupes. J Sci Food Agric 90:17501758 (2010).

15 Guinda A, Castellano J M, Santos-Lozano J M, Delgado-Hervás T, GutiérrezAdánez P and Rada M, Determination of major bioactive compounds from olive leaf. LWT-Food Sci Technol 64, 431-438 (2015).

16 Bianchi $\mathrm{G}$ and Vlahov G, Composition of lipids classes in the morphologically parts of the olive fruit, cv. Coratina (Olea europaea Linn.). Fat Sci Technol 96:72-77 (1994).

17 Servili M, Baldioli M, Selvagini R, Macchioni A and Montedoro G F, Phenolic compounds of olive fruits: one-and-two-dimensional nuclear magnetic resonance characterization of nüzhenide and its distribution in the constitutive parts of fruit. J Agric Food Chem 47:12-18 (1999).

18 Ramírez E, Medina E, Brenes M and Romero C, Endogenous enzymes involved in the transformation of oleuropein in Spanish table olive varieties. J Agric Food Chem 62:9569-9575 (2014).

19 Ranalli A, Contento S, Lucera L, Di Febo M, Marchegiani D and Di Fonzo V, Factors affecting the contents of iridoid oleuropein in olive leaves (Olea europaea L). J Agric Food Chem 54:434-440 (2006).

20 Ortega-García F and Peragón J, Phenylalanine ammonia-lyase and phenolic compounds in leaves and fruits of Olea europaea L. cv. Picual during ripening. J Sci Food Agric 89:298-406 (2009).

21 Fabbri A, Galaverna G and Ganino T, Polyphenol composition of olive leaves with regard to cultivar, time of collection and shoot type. Acta Hort 791:459-464 (2008). 
22 Ranalli A, Marchegiani D, Contento S, Girardi F, Nicolosi M P and Brullo M D, Variations of iridoid oleuropein in Italian olive varieties during growth and maturation. Eur J Lipid Sci Technol 111:678-687 (2009).

23 Cecchi L, Migliorini M, Cherubini C, Giusti M, Zanoni B, Innocenti M and Mulinacci N, Phenolic profiles, oil amount and sugar content during olive ripening of three typical Tuscan cultivars to detect the best harvesting time for oil production. Food Res Int 54:1876-1884 (2013).

24 Talhaoui N, Gómez-Caravaca A, León L, De la Rosa R, Fernández-Gutiérrez A and Segura-Carretero A, Pattern of variation of fruit traits and phenol content in olive fruits from six different cultivars. J Agric Food Chem 63:10466-10467 (2015c).

25 Medina E, Brenes M, Romero C, García A and De Castro A, Main antimicrobial compounds in table olives. J Agric Food Chem 55:9817-9823 (2007).

26 Ramírez E, Gandul-Rojas B, Romero C, Brenes M and Gallardo-Guerrero L, Composition of pigments and colour changes in green table olives related to processing type. Food Chem 166:115-124 (2015).

27 Silva S, Gomes L, Leitao F, Bronze M, Coelho A and Boas L V, Secoiridoids in olive seed: characterization of nuzhenide and 11-methyl oleosides by liquid chromatography with diode array and mass spectrometry. Grasas Aceites 61:157-164 (2010).

28 Di Donna, L, Mazzotti F, Naccarato A, Salerno R, Tagarelli A, Taverna D and Sindona G, Secondary metabolites of Olea europaea leaves as markers for the discrimination of cultivar and cultivation zones by multivariate analysis. Food Chem 121:492-496 (2010).

29 Sahin S, Malik N S A, Pérez J L and Brockington J E, Seasonal changes of individual phenolic compounds in leaves of twenty olive cultivars grown in Texas. J Agric Sci Technol B2:242-247 (2012).

30 Mert C, Barut E and Ipek A, Quantitative seasonal changes in the leaf phenolic content related to the alternate-bearing patterns of olive (Olea europaea L. $c v$. Gemlik). J Agric Sci Technol 15:995-1006 (2013).

31 Fernández-Hernández A, Martínez A, Rivas F, García-Mesa J A and Parra A, Effect of the solvent and the simple preparation on the determination of triterpene compounds in two-phase olive-mill-waste samples. J Agric Food Chem 63:4269-4275 (2015). 
32 Peragón J, Time course of pentacyclic triterpenoids from fruits and leaves of olive tree (Olea europaea L.) cv. Picual and cv. Cornezuelo during ripening. J Agric Food Chem 61:6671-6678 (2013).

33 García P, Brenes M, Romero C and Garrido A, Respiration and physicochemical changes in harvested olive fruits. J Hort Sci 70:925-933. (1995).

34 Gómez-González S, Ruiz-Jiménez J, Priego-Capote F and Luque de Castro M $\mathrm{D}$, Qualitative and quantitative sugar profiling in olive fruits, leaves, and stems by gas chromatography-tandem mass spectrometry (GC-MS/MS) after ultrasound-assisted leaching. J Agric Food Chem 58:12292-12299 (2010). 


\section{Figure legends}

Figure. 1. Concentration of total phenolic compounds $\left(\mathrm{mg} \mathrm{kg}^{-1}\right)$ in Picual olives harvested in December with green and black surface color, and Picual leaves collected in November and April. Samples were obtained from three different orchards during the 2012/2013 and 2013/2014 seasons. CH, Chillluevar, ST, Santistebandel Puerto, VI, Villacarrillo. Vertical bars with different letters indicate significant differences between orchards according to Duncan's multiple-range test $(p<0.05)$.

Figure.2. Concentration $\left(\mathrm{mg} \mathrm{kg}^{-1}\right)$ of triterpenic acids in the olives of the Picual (P) and Arbequina (A) cultivars collected with different surface color in December during the 2012/2013 season. Bars mean the data of 7 samples of Picual olives analyzed in triplicate, and the mean of one sample of Arbequina olives analyzed in triplicate. Triplicate samples were obtained from three different olive trees. Vertical bars with different letters indicate significant differences between cultivars according to Duncan's multiple-range test $(p<0.05)$.

Figure. 3. Concentration $\left(\mathrm{mg} \mathrm{kg}^{-1}\right)$ of triterpenic acids in the leaves of the Picual (P) and Arbequina(A) cultivars collected from November to April during the 2012/2013 season. Bars mean the data of 7 samples of Picual leaves analyzed in triplicate, and the mean of one sample of Arbequina leaves analyzed in triplicate. Triplicate samples were obtained from three different olive trees. Vertical bars with different letters indicate significant differences between cultivars according to Duncan's multiple-range test $(p<0.05)$.

Figure. 4. Concentration of total triperpenic acids $\left(\mathrm{mg} \mathrm{kg}^{-1}\right)$ in Picual olives harvested in December with green and black surface color, and Picual leaves collected in November and April. Samples were obtained from three different orchards during the 2012/2013 and 2013/2014 seasons. CH, Chillluevar, ST, Santistebandel Puerto, VI, Villacarrillo.Vertical bars with different letters indicate significant differences between orchards according to Duncan's multiple-range test $(p<0.05)$.

Figure. 5. Concentration of sugars $\left(\mathrm{mg} \mathrm{kg}^{-1}\right)$ in Picual and Arbequina olives harvestedin December with green and black surface color, and Picual and Arbequina leaves collected in November and April. Data are the mean of 4 samples from 4 different orchards. Vertical bars with different letters indicate significant differences between 
cultivars according to Duncan's multiple-range test $(p<0.05)$. S, sucrose, G, glucose, $\mathrm{F}$, fructose, and M, mannitol. 


\section{Table 1}

Phenolic compounds $\left(\mathrm{mg} \mathrm{kg}^{-1}\right)$ in olive leaves of the Picual and Arbequina cultivars collected from November to April. They were analyzed during the 2012/2013 season.

\begin{tabular}{|c|c|c|c|c|c|c|c|c|c|}
\hline \multirow[b]{2}{*}{ Month } & \multicolumn{2}{|c|}{ Oleuropein } & Hy 4-glucoside ${ }^{y}$ & \multicolumn{2}{|c|}{ Hy 1-glucoside } & \multicolumn{2}{|c|}{ Verbascoside } & \multicolumn{2}{|c|}{ Others } \\
\hline & Picual & Arbequina Picual & Arbequina & Picual & Arbequina & Picual & Arbequina & Picual & Arbequina \\
\hline January & $54018(5688) \mathrm{b}$ & $32539(5978) b 1124(592) a$ & $1853(430) b$ & 337 (219)a & $381(55) \mathrm{b}$ & $805(445) \mathrm{a}$ & $856(322) b$ & $218(164) \mathrm{a}$ & $338(79) \mathrm{a}$ \\
\hline April & $47468(6501) \mathrm{b}$ & $30456(5955) \mathrm{b} 2550(575) \mathrm{b}$ & $3332(712) \mathrm{c}$ & $424(101) \mathrm{a}$ & $954(67) \mathrm{c}$ & $1263(708) \mathrm{a}$ & $1026(283) \mathrm{b}$ & $262(222) \mathrm{a}$ & $594(80) \mathrm{b}$ \\
\hline
\end{tabular}


Table 2

Phenolic compounds $\left(\mathrm{mg} \mathrm{kg}^{-1}\right)$ in the pulp of olives of the Picual and Arbequina cultivars harvested with different degree of maturation. They were analyzed during the $2012 / 2013$ season.

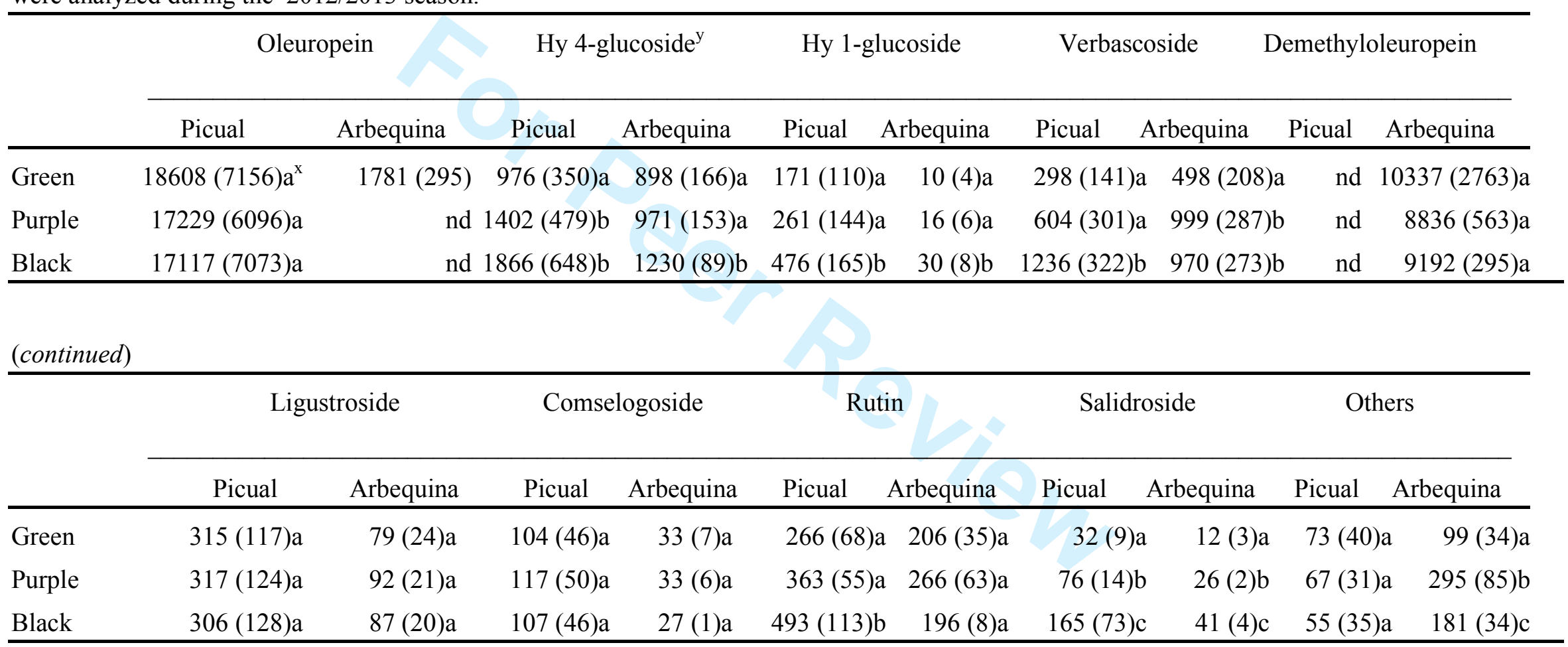

${ }^{\mathrm{x}}$ Data are the mean of 7 samples of Picual olives and one of Arbequina leaves analyzed in triplicate. Standard deviation is shown in parentheses. ${ }^{b} \mathrm{Hy}$ 4-glucoside, Hydroxytyrosol 4-glucoside; Hy-1-glucoside, Hydroxytyrosol 1-glucoside; others: vanillic, caffeic and $p$-coumaric acids, luteolin-7glucoside and caffeoyl-6-secologanoside. Column values followed by the same letter do not differ at the $5 \%$ level of significance according to Duncan's multiple-range test. 


\section{Table 3}

Concentration $\left(\mathrm{mg} \mathrm{kg}^{-1}\right)$ of phenolic and triterpenic acids in different parts of Picual olives harvested with green and black surface color. Data are the mean of 4 samples collected from 4 different growers.

\begin{tabular}{|c|c|c|c|c|c|c|}
\hline \multirow[b]{2}{*}{ Compound } & \multicolumn{3}{|c|}{ Green/yellow olives } & \multicolumn{3}{|c|}{ Black olives } \\
\hline & Skin & Pulp & Seed & Skin & Pulp & Seed \\
\hline Oleuropein & $27937(5655)$ & $16760(3960)$ & $183(82)$ & $25714(7418)$ & $11080(4744)$ & 325 (167) \\
\hline Nuzhenide & $\mathrm{nd}^{\mathrm{b}}$ & nd & $4042(335)$ & nd & nd & 3759 (1205) \\
\hline Total phenolics ${ }^{\mathrm{a}}$ & $31788(5601)$ & 19438 (3292) & $5128(261)$ & $310500(61097)$ & $14787(4481)$ & $5138(1090)$ \\
\hline Oleanolic acid & $4356(2120)$ & $59(23)$ & nd & 3094 (1116) & $27(22)$ & nd \\
\hline Maslinic acid & 7209 (3527) & $393(210)$ & nd & $5556(1935)$ & $147(109)$ & nd \\
\hline
\end{tabular}

${ }^{a}$ Total phenolics is the sum of oleuropein, nuzhenide, hydroxytyrosol 1-glucoside, hydroxytyrosol 4-glucoside, salidroside, vanillic, caffeic and $p$ coumaric acids, verbascoside, comselogoside, caffeoyl-6-secologanoside, luteolin 7-glucoside, rutin and ligustroside. ${ }^{\mathrm{b}}$ nd, not detected. Standard deviation is shown in parentheses. 


\section{Table S1}

Moisture $\left(\mathrm{g} \mathrm{kg}^{-1}\right)$ of leaves of the Picual and Arbequina varieties collected from November to April. They were analyzed during the 2012/2013 and 2013/2014 seasons.

\begin{tabular}{|c|c|c|c|c|}
\hline \multirow[b]{2}{*}{ Month } & \multicolumn{2}{|c|}{ Season $2012 / 2013$} & \multicolumn{2}{|c|}{ Season $2013 / 2014$} \\
\hline & Picual & Arbequina & Picual & Arbequina \\
\hline January & $455(18)$ & $524(23)$ & $457(2)$ & $517(2)$ \\
\hline April & $409(15)$ & $543(30)$ & $427(16)$ & $474(2)$ \\
\hline
\end{tabular}

${ }^{\mathrm{a}}$ Data are the mean of 7 and 3 samples of leaves of the Picual variety collected during the seasons 2012/2013 and 2013/2104 respectively. ${ }^{\mathrm{b}}$ Data are the mean of 3 samples of leaves of the Arbequina variety. Standard deviation is shown in parentheses. 


\section{Table S2}

Oleosidic compounds $\left(\mathrm{mg} \mathrm{kg}^{-1}\right)$ in olive leaves of the Picual and Arbequina cultivars collected from November to April. They were analyzed during the 2012/2013 season.

\begin{tabular}{|c|c|c|c|c|c|c|c|c|}
\hline \multirow[b]{2}{*}{ Month } & \multicolumn{2}{|c|}{ Oleoside } & \multicolumn{2}{|c|}{ Secoxyloganin } & \multicolumn{2}{|c|}{ Secologanoside } & \multicolumn{2}{|c|}{ Oleoside-11-methyl ester } \\
\hline & Picual & Arbequina & Picual & Arbequina & Picual & Arbequina & Picual & Arbequina \\
\hline January & $2660(369) a$ & $1730(532) b$ & $660(323) a$ & $852(506) \mathrm{a}$ & $721(233) b$ & $1079(328) b$ & $865(170) b$ & $494(78) b$ \\
\hline April & $2398(325) a$ & $1372(485) b$ & $281(182) b$ & 299 (129)b & $461(207) b$ & $1068(248) b$ & $607(180) \mathrm{b}$ & $425(88) c$ \\
\hline
\end{tabular}

${ }^{\mathrm{x}}$ Data are the mean of 7 samples of Picual leaves analyzed in triplicate, and the mean of Arbequina leaves analyzed in triplicate. Standard deviation is shown in parentheses. Column values followed by the same letter do not differ at the $5 \%$ level of significance according to Duncan's multiplerange test. 


\section{Table S3}

Moisture $\left(\mathrm{g} \mathrm{kg}^{-1}\right)$ of the pulp of olives of the Picual and Arbequina cultivars harvested with different surface color. They were analyzed during the 2012/2013 and 2013/2014 seasons.

\begin{tabular}{|c|c|c|c|c|}
\hline \multirow[b]{2}{*}{ Colour } & \multicolumn{2}{|c|}{ Season $2012 / 2013$} & \multicolumn{2}{|c|}{ Season $2013 / 2014$} \\
\hline & Picual & Arbequina & Picual & Arbequina \\
\hline Purple & $666(35)$ & 718 (14) & $594(22)$ & $613(1)$ \\
\hline Black & $653(38)$ & 704 (17) & $583(39)$ & $630(1)$ \\
\hline
\end{tabular}




\section{Table S4}

Oleosidic compounds $\left(\mathrm{mg} \mathrm{kg}^{-1}\right)$ in the pulp of olives of the Picual and Arbequina cultivars harvested with different color on their surface. They were analyzed during the 2012/2013 season.

\begin{tabular}{|c|c|c|c|c|c|c|}
\hline \multirow[b]{2}{*}{ Compound } & \multicolumn{2}{|c|}{ Green/yellow } & \multicolumn{2}{|c|}{ Purple } & \multicolumn{2}{|c|}{ Black } \\
\hline & Picual & Arbequina & Picual & Arbequina & Picual & Arbequina \\
\hline Secoxyloganin & $716(413) a$ & $1714(412) b$ & $398(383) \mathrm{a}$ & $502(127) \mathrm{a}$ & 264 (194)a & $292(18) a$ \\
\hline Secologanoside & 1789 (669)a & 1345 (375)a & $1599(666) \mathrm{a}$ & $1072(110) a$ & 1447 (549)a & $1110(84) \mathrm{a}$ \\
\hline
\end{tabular}

${ }^{\mathrm{x}}$ Data are the mean of 7 samples of Picual olives and one of Arbequina leaves analyzed in triplicate. Standard deviation is shown in parenthesis. Column values followed by the same letter do not differ at the $5 \%$ level of significance according to Duncan's multiple-range test. 


\section{Table S5}

Concentration ( $\mathrm{m} \mathrm{kg}^{-1}$ ) of oleosidic compounds in different parts of Picual olives harvested with green and black surface color. Data are the mean of 4 samples collected from 4 different growers. Standard deviation is shown in parentheses.

\begin{tabular}{|c|c|c|c|c|c|c|}
\hline \multirow[b]{2}{*}{ Compound } & \multicolumn{3}{|c|}{ Green olives } & \multicolumn{3}{|c|}{ Black olives } \\
\hline & Skin & Pulp & Seed & Skin & Pulp & Seed \\
\hline Oleoside & $697(146)$ & $453(141)$ & nd & $560(172)$ & $337(141)$ & nd \\
\hline Secoxyloganin & $\mathrm{nd}^{\mathrm{a}}$ & $881(271)$ & nd & nd & 565 (169) & nd \\
\hline Secologanoside & $2475(341)$ & $1832(449)$ & nd & $1825(684)$ & $1363(540)$ & nd \\
\hline Oleoside 11-methyl ester & $1150(442)$ & $5296(3391)$ & nd & $1385(896)$ & $4188(3426)$ & nd \\
\hline
\end{tabular}

${ }^{a}$ Not detected. 

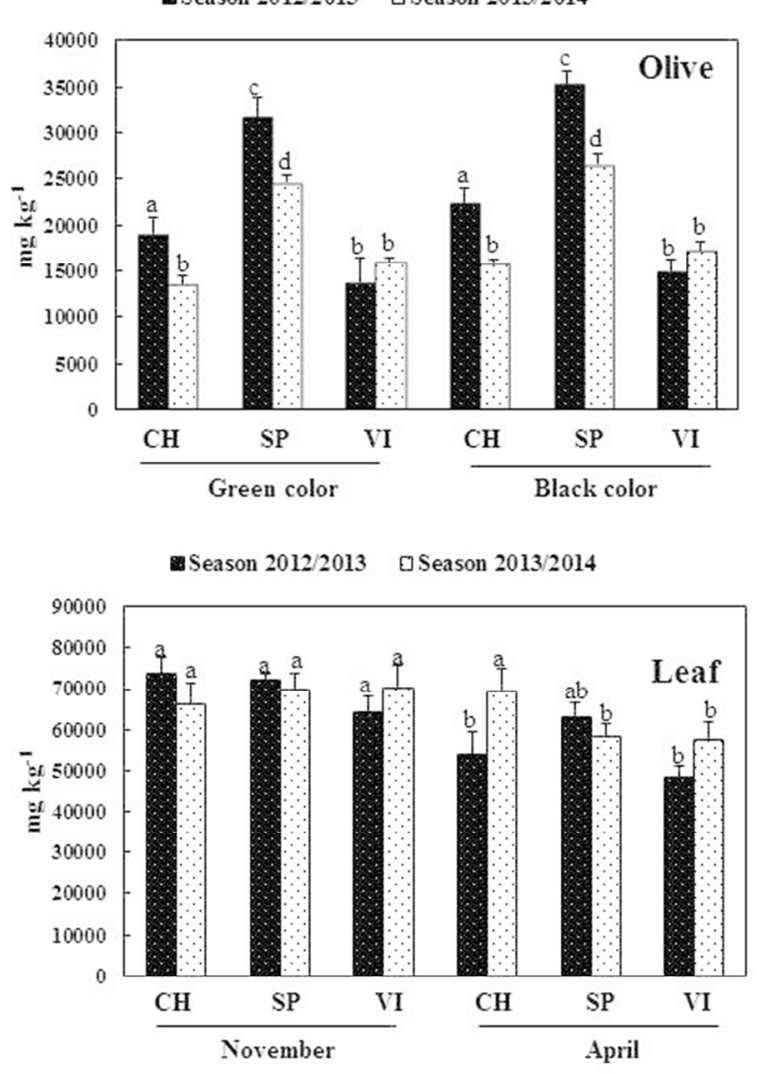

\footnotetext{
Figure 1
$190 \times 254 \mathrm{~mm}(96 \times 96 \mathrm{DPI})$

Figure 1
$190 \times 254 \mathrm{~mm}(96 \times 96$ DPI $)$
} 


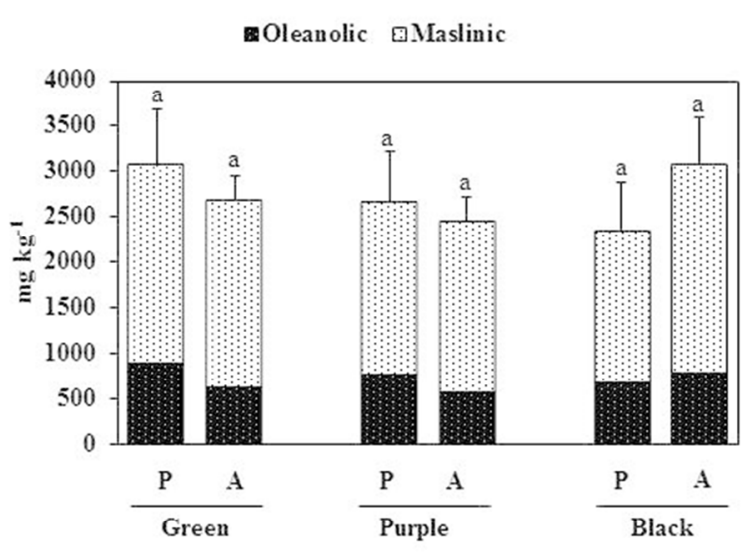

Figure 2 $190 \times 254 \mathrm{~mm}(96 \times 96 \mathrm{DPI})$

JSFA@wiley.com 


1
2
3
4
5
6
7
8
9
10
11
12
13
14
15
16
17
18
19
20
21
22
23
24
25
26
27
28
29
30
31
32
33
34
35
36
37
38
39
40
41
42
43
44
45
46
47
48
49
50
51
52
53
54
55
56
57
58
60

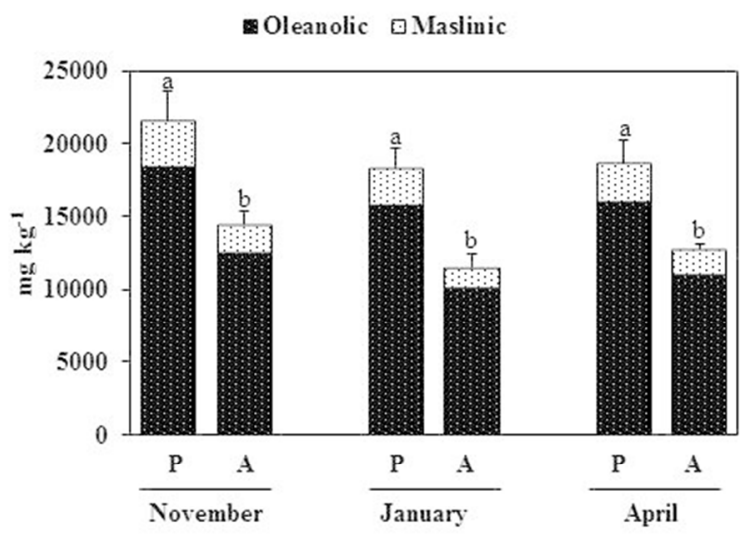

Figure 3 $190 \times 254 \mathrm{~mm}(96 \times 96 \mathrm{DPI})$

JSFA@wiley.com 

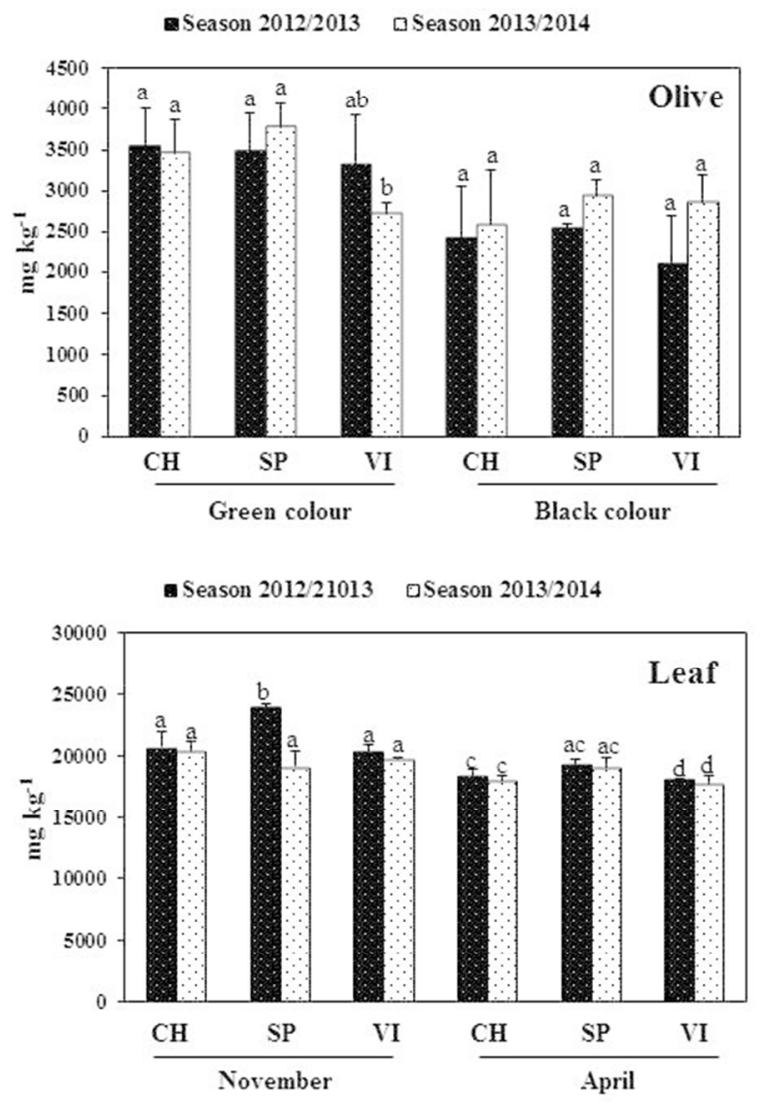

Figure 4 $190 \times 254 \mathrm{~mm}(96 \times 96 \mathrm{DPI})$ 

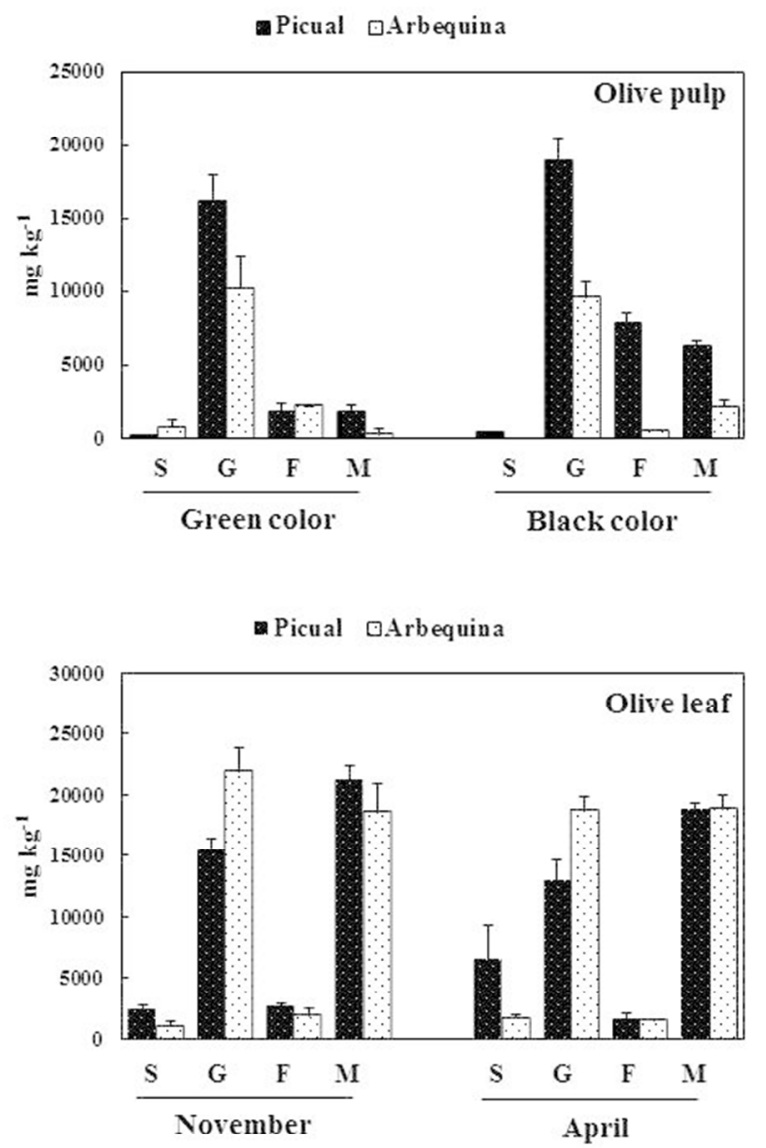

Figure 5 $190 \times 254 \mathrm{~mm}(96 \times 96 \mathrm{DPI})$ 